\title{
Эпитаксия слоев GaN(0001) или GaN(1011) на подложке Si(100)
}

\author{
() В.Н. Бессолов, М.Е. Компан, Е.В. Коненкова, В.Н. Пантелеев, С.Н. Родин, М.П. Щеглов \\ Физико-технический институт им. А.Ф. Иоффре РАН, Санкт-Петербург, Россия \\ E-mail: bes.triat@mail.ioffe.ru
}

Поступило в Редакцию 26 февраля 2019г.

В окончательной редакции 6 марта 2019г.

Принято к публикации 7 марта 2019г.

\begin{abstract}
Экспериментально продемонстрированы два разных подхода при эпитаксии слоев толщиной $4 \mu \mathrm{m}$ полярного $\mathrm{GaN}(0001)$ или полуполярного $\mathrm{GaN}(10 \overline{1} 1)$ на $V$-образной наноструктурированной подложке $\mathrm{Si}(100)$ с нанометровыми буферными слоями $\mathrm{SiC}$ и $\mathrm{AlN}$. Слои $\mathrm{GaN}(0001)$ были синтезированы методом хлоридгидридной газофазной эпитаксии, а $\mathrm{GaN}(10 \overline{1} 1)$ - методом газофазной эпитаксии из металлоорганических соединений с последующим доращиванием путем хлорид-гидридной газофазной эпитаксии. Показано, что слои полярного $\mathrm{GaN}(0002)$ имеют величину продольных упругих напряжений $-0.45 \mathrm{GPa}$ и минимальную полуширину кривой качания рентгеновской дифракции $\omega_{\theta} \sim 45 \operatorname{arcmin}$, а для полуполярного $\mathrm{GaN}(10 \overline{1} 1)$ эти величины составляют $-0.29 \mathrm{GPa}$ и $\omega_{\theta} \sim 22 \operatorname{arcmin}$ соответственно. Сделан вывод о перспективности комбинированной технологии полуполярного нитрида галлия на подложке кремния ориентации (100).
\end{abstract}

Ключевые слова: полуполярный нитрид галлия, комбинационное рассеяние света, газофазная эпитаксия.

DOI: 10.21883/PJTF.2019.11.47813.17756

Кремниевая интегральная электроника, продолжающая следовать закону Мура, приближается к физическому пределу [1], дальнейшее развитие технологии для полупроводниковых интегральных схем становится все сложнее [2]. Вероятно, перспектива развития интегральной электроники связана с синтезом прежде всего нитрида галлия и кремния ориентации (100). Первая попытка интеграции транзисторов $\mathrm{GaN}$ на Si-пластине „кремний на изоляторе“ включала в себя механическое соединение подложки $\mathrm{Si}(111)$ и приборного слоя $\mathrm{Si}(100)$, в которых на поверхности $\mathrm{Si}(111)$ выращивалась эпитаксиальная структура GaN-транзисторов, а на $\mathrm{Si}(100)-$ интегральная схема [3]. Попытки синтезировать гексагональный нитрид галлия непосредственно на подложке $\mathrm{Si}(100)$ показали, что эпитаксия $\mathrm{GaN}(0001)$ на $\mathrm{Si}(100)$ в отличие от $\mathrm{Si}(111)$ приводит к низкокачественной структуре [4].

Это связано прежде всего с тем, что при эпитаксии гексагональной структуры $\mathrm{GaN}$ на планарной кубической структуре $\mathrm{Si}(100)$ слои растут в двух кристаллографических ориентациях, развернутых относительно друг друга [4]. Чтобы избежать этого негативного явления, для эпитаксии $\mathrm{GaN}(0001)$ предложено использовать подложки $\mathrm{Si}(100)$, разориентированные на $3-7^{\circ}$ в направлении $\langle 110\rangle$. Так, методом молекулярно-пучковой эпитаксии (MBE) на подложке $\mathrm{Si}(100)$, разориентированной на $4^{\circ}$, был синтезирован слой $\mathrm{GaN}(0002)$ толщиной $400 \mathrm{~nm}$ с полушириной кривой рентгеновской дифракции $\omega_{\theta}=45 \operatorname{arcmin}$ [5]. Методом хлорид-гидридной газофазной эпитаксии (HVPE) на разориентированной на $4-7^{\circ}$ подложке синтезировался полуполярный $\mathrm{GaN}(20 \overline{2} 3)$ с $\omega_{\theta} \sim 24 \operatorname{arcmin}[6]$. Известен метод синтеза гексагонального нитрида галлия на подложке $\mathrm{Si}(100)$, в котором буферный слой $\mathrm{Al}$ был получен методом пульсирующего лазерного напыления, а слой $\mathrm{GaN}$ выращен методом MBE. Такая технология позволила получить 300-нанометровый слой $\mathrm{GaN}(0002)$ с полушириной кривой рентгеновской дифракции $\omega_{\theta}=0.45^{\circ}$ [7]. В последнее время для снижения деформаций в слое нитрида галлия используют наноструктурированные подложки $\mathrm{Si}(001)$, на поверхности которых сформированы канавки [8]. Однако все упомянутые подходы не дают удовлетворительного результата для решения проблемы интеграции $\mathrm{GaN}$ на специально неразориентированную подложку $\mathrm{Si}(100)$, которая в основном применяется в электронике, и дальнейший поиск в этом направлении необходим.

Настоящая работа посвящена сравнению эпитаксии $\mathrm{GaN}(0001)$ и $\mathrm{GaN}(10 \overline{1} 1)$ на наноструктурированной подложке $\mathrm{Si}(100)$ и структурных свойств слоев.

Для выполнения поставленной цели на подложке $\mathrm{Si}(100)$ толщиной $400 \mu \mathrm{m}$ с точностью ориентации поверхности $\pm 0.5^{\circ}$ синтезировались два типа слоев: $\mathrm{GaN}(0001)$ либо $\mathrm{GaN}(10 \overline{1} 1)$. Для всех типов слоев по технологии Wostec [9] формировалась $V$-образная наноструктурированная поверхность подложки $N P-\operatorname{Si}(100)$. В результате поверхность $\mathrm{Si}(100)$ имела „нанохребты“ с величиной периода между ними $110 \mathrm{~nm}$ и высотой „хребта“ $55 \mathrm{~nm}$. Видно, что $N P$-Si(100) имеет грани, которые соответствуют плоскости с углом наклона около $54^{\circ},-\operatorname{Si}(111)$ (рис. 1,a). Перед эпитаксией слоев нитридов алюминия и галлия подложки $N P-\mathrm{Si}(100)$ покрывались слоем $\mathrm{SiC}$ толщиной около $50 \mathrm{~nm}$ (аналогично [10]).

Эпитаксиальный рост полярных слоев осуществлялся методом HVPE в соответствии с технологией $\mathrm{GaN}$ для разориентированной подложки $\operatorname{Si}(100)$ [6]. Эпитаксиальный рост полуполярных слоев $\mathrm{GaN}(10 \overline{1} 1)$ осуществлял- 


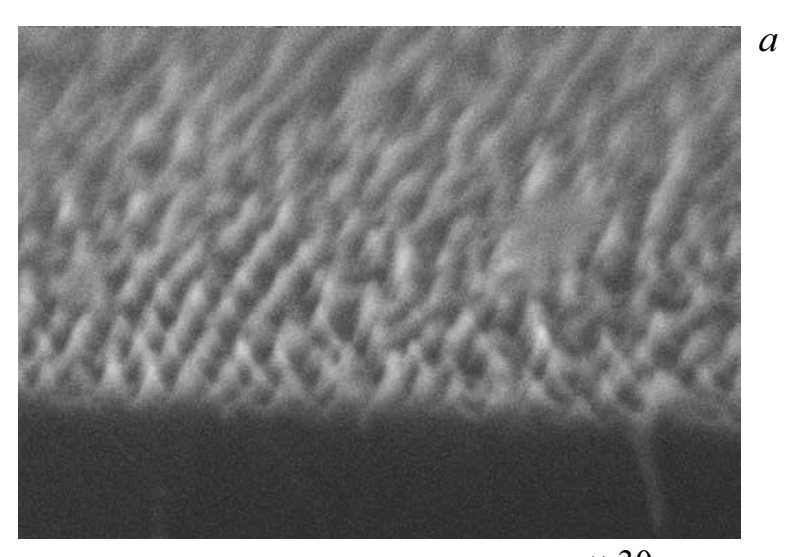

$+30 \mathrm{~nm}$
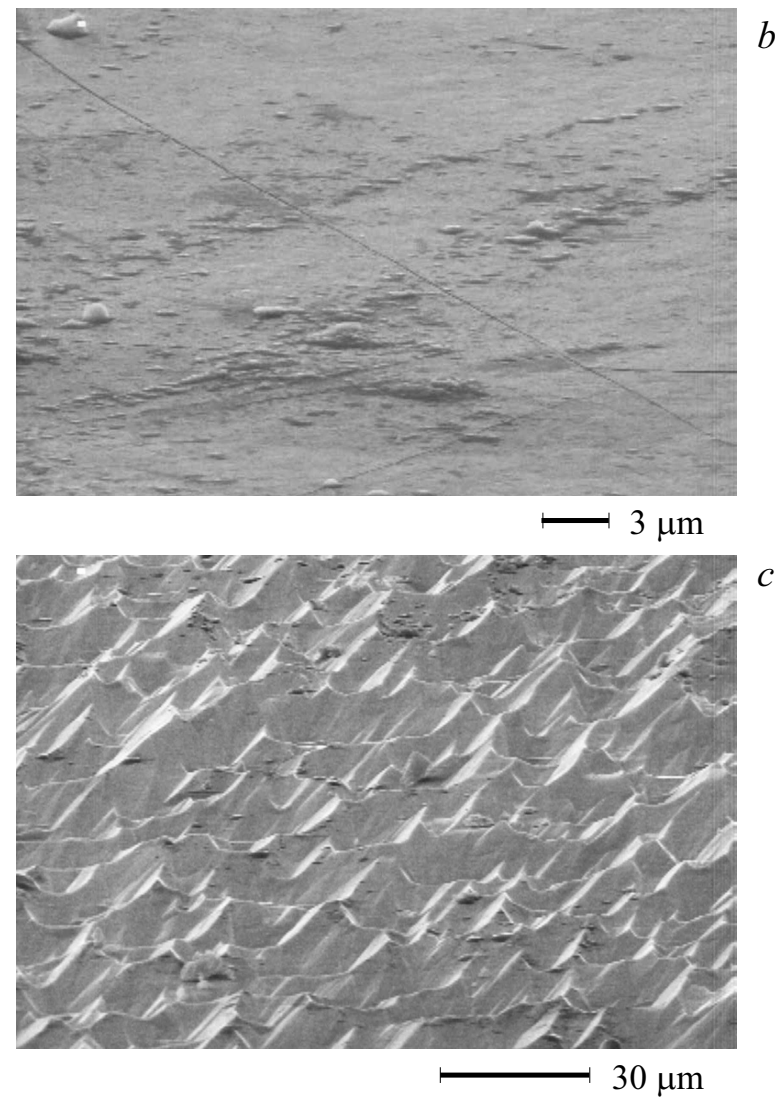

Рис. 1. РЭМ-изображения поверхности подложки $N P-\operatorname{Si}(100)(a) \quad$ и поверхностей $\operatorname{GaN}(0001) \quad(b) \quad$ и $\mathrm{GaN}(10 \overline{1} 1)(c)$, синтезированных на подложке $N P-\mathrm{Si}(100)$.

ся сначала методом газофазной эпитаксии из металлоорганических соединений (MOCVD) аналогично [10], a затем слой $\mathrm{GaN}$ толщиной $4 \mu \mathrm{m}$ синтезировался методом HVPE по технологии [6]. Структурные характеристики слоев $\mathrm{GaN}$ определялись методами рентгеновской дифрактометрии (РД), растровой электронной микроскопии (РЭМ), комбинационного рассеяния света (КРС). КРС изучалось с помощью рамановского спектрометра MRS 320. Источником света являлся гелийнеоновый лазер с длиной волны излучения $632.8 \mathrm{~nm}$.
Исследования проводились при комнатной температуре аналогично [11].

Экспериментальные результаты для слоев $\mathrm{GaN}(0001)$ таковы: РД-анализ показал, что полярный $\mathrm{GaN}(0002)$, синтезированный на подложке $N P-\operatorname{Si}(100)$, имеет полуширину кривой качания $\omega_{\theta} \sim 45 \operatorname{arcmin}$. Следует отметить, что полярный слой $\mathrm{GaN}(0002)$, синтезированный для сравнения на подложке $\mathrm{Si}(111)$ в таком же температурно-временно́м режиме, имеет $\omega_{\theta} \sim 15$ arcmin. Согласно данным РД-анализа, для полуполярного $\mathrm{GaN}(10 \overline{1} 1)$ толщиной $1 \mu \mathrm{m}$, синтезированного методом MOCVD, полуширина кривой рентгеновской дифракции $\omega_{\theta} \sim 45 \operatorname{arcmin}$, a выращенный на этом слое уже методом HVPE $\mathrm{GaN}(10 \overline{1} 1)$ толщиной $4 \mu \mathrm{m}$ имеет $\omega_{\theta} \sim 22$ arcmin.

Изображения, полученные при помощи РЭМ, позволили выявить (рис. $1, b, c)$, что поверхность $\mathrm{GaN}(0001)$ на $\mathrm{NP}-\mathrm{Si}(100)$ имеет существенно меньшую шероховатость, чем поверхность $\mathrm{GaN}(10 \overline{1} 1)$, однако $\mathrm{GaN}(0001)$ содержит на поверхности трещины (рис. $1, b$ ).

Спектры КРС, измеренные в области фононной моды $E_{2}($ high), для слоев $\mathrm{GaN}$, выращенных на $N P-\mathrm{Si}(100)$ методом HVPE, приведены на рис. 2. Спектры КРС слоев $\mathrm{GaN}(0001)$ и $\mathrm{GaN}(10 \overline{1} 1)$ в целом соответствовали тому, что можно было ожидать: содержали линии, принадлежащие кремниевой подложке, линии, характерные для $\mathrm{SiC}$, аналогичные опубликованным в [11], и пики $E_{2}($ high), обусловленные GaN. Положение пика $E_{2}($ high) зависит от подложки и кристаллографической плоскости поверхности структуры: $566.1 \mathrm{~cm}^{-1}$ для $\mathrm{GaN}(0001) / N P-\mathrm{Si}(100)$ и $566.8 \mathrm{~cm}^{-1}$ для $\mathrm{GaN}(10 \overline{1} 1) / N P-\mathrm{Si}(100)$ (рис. 2). Для сравнения пик $E_{2}($ high) для структуры $\mathrm{GaN}(0001) / \mathrm{Si}(111)$ располагался при $566.2 \mathrm{~cm}^{-1}$.

Процесс синтеза $\mathrm{GaN}(0001)$ и $\mathrm{GaN}(10 \overline{1} 1)$ на одинаковых наноструктурированных подложках $N P-\mathrm{Si}(100)$ можно представить следующим образом.

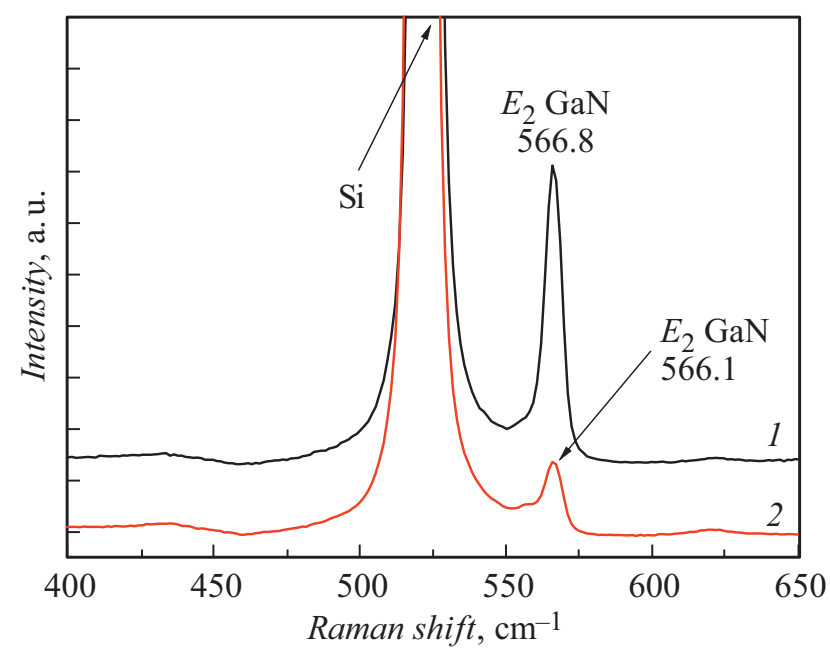

Рис. 2. Спектры КРС структур $\mathrm{GaN}(10 \overline{1} 1) / N P-\operatorname{Si}(100)$ (1) и $\mathrm{GaN}(0001) / N P-\mathrm{Si}(100)(2)$. 

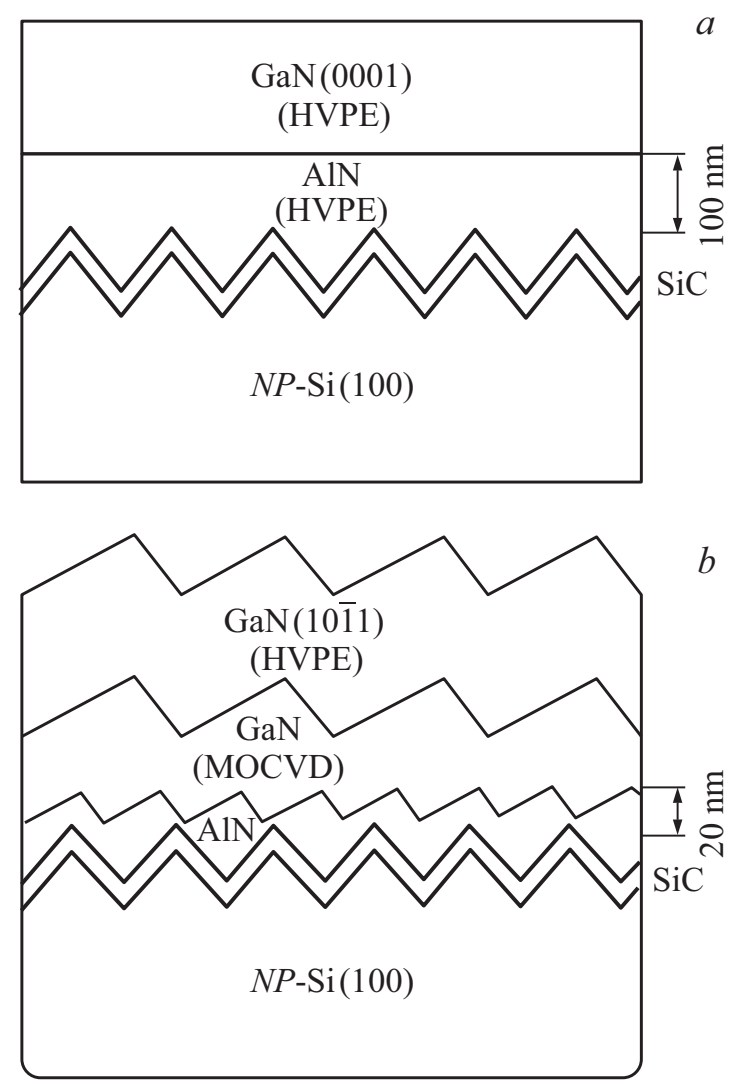

Рис. 3. Схема формирования слоев $\operatorname{GaN}(0001)$ (a) и $\mathrm{GaN}(10 \overline{1} 1)(b)$ на подложке $N P-\operatorname{Si}(100)$.

Как известно [12], слои AlN на подложке $\mathrm{Si}(100)$ с буферным слоем $\mathrm{SiC}$ зарождаются в виде столбчатых доменов. При эпитаксии $\mathrm{AlN}$ на $\mathrm{SiC} / \mathrm{Si}(100)$ в методе HVPE из-за больших скоростей синтеза размеры гексагональных блоков AlN становятся крупнее, чем рельеф поверхности $N P-\mathrm{Si}(100)$, а сплошной эпитаксиальный слой формируется при толщинах около $80 \mathrm{~nm}$. Такой толстый по сравнению с рельефом слой AlN приводит к росту монокристаллических слоев полярного нитрида галлия $\mathrm{GaN}(0001)$ (рис. 3,a) с полушириной кривой качания $\omega_{\theta} \sim 45 \operatorname{arcmin}$.

При эпитаксии AlN и GaN методом MOCVD на подложках $\mathrm{SiC} / N P-\mathrm{Si}(100)$ происходит формирование сплошного слоя AIN при скоростях, существенно меньших, чем при HVPE, и это сохраняет „нанохребты“ на поверхности слоя. В дальнейшем растет уже полуполярный $\mathrm{GaN}(10 \overline{1} 1)$ аналогично [10] (рис. 3,b). Последующий синтез $\mathrm{GaN}(10 \overline{1} 1)$ методом HVPE показал рост слоя в том же кристаллографическом направлении, но величина полуширины кривой рентгеновской дифракции уменьшалась до $\omega_{\theta} \sim 22$ arcmin.

Из данных по КРС хорошо видно, что положение пика линии $E_{2}(h i g h)$ для слоев $\mathrm{GaN}$ сдвинуто в низкочастотную сторону по отношению к его положению в недеформированном слое (при оценке принималось, что для ненапряженной структуры положение
$E_{2}($ high $\left.)=568 \mathrm{~cm}^{-1}[13]\right)$. Этот факт свидетельствует в пользу наличия деформации растяжения $\mathrm{GaN}$ в плоскости, параллельной плоскости подложки, а различная величина сдвига максимума пика $E_{2}(h i g h)$ указывает на разную величину остаточной деформации. Для слоев $\mathrm{GaN}(0001)$ и $\mathrm{GaN}(10 \overline{1} 1)$ исходя из спектров КРС оценивалась величина продольных упругих напряжений, которая составила -0.45 и $-0.29 \mathrm{GPa}$ соответственно.

Таким образом, сравнение свойств слоев $\mathrm{GaN}(0001)$ и $\mathrm{GaN}(10 \overline{1} 1)$, синтезированных на подложке $N P-\mathrm{Si}(100)$, показывает, что эпитаксия полуполярного нитрида галлия предпочтительнее для интеграции с подложкой $\mathrm{Si}(100)$.

\section{Благодарности}

Авторы благодарят компанию ООО „Квантовый кремний“ (Москва, Россия) за предоставление образцов подложек $N P-\mathrm{Si}(100)$, наноструктурированных по технологии Wostec, а также C.A. Кукушкина и В.В. Лундина за стимулирование работы в данном направлении.

\section{Конфрликт интересов}

Авторы заявляют, что у них нет конфликта интересов.

\section{Список литературы}

[1] Lin Q., Wu H., Jia G. // Circuits and Systems. 2018. V. 9. P. 9-21.

[2] Cui Z. Nanofabrication: principles, capabilities and limits. 2nd ed. Springer, 2017. $432 \mathrm{p}$.

[3] Chung J.W., Ryu K., Lu B., Palacios T. // Proc. European Solid-State Device Research Conf. (ESSDERC). Sevilla, Spain, 2010. P. 52-56.

[4] Бессолов В.Н., Гущина Е.В., Коненкова Е.В., Коненков С.Д., Львова Т.В., Пантелеев В.Н., Щеглов М.П. // ЖТФ. 2019. Т. 89. В. 4. С. 574-577.

[5] Joblot S., Semond F., Natali F., Vennégués P., Laügt M., Cordier Y., Massies J. // Phys. Status Solidi C. 2005. V. 2. P. 2187-2190.

[6] Bessolov V., Kalmykov A., Konenkova E., Kukushkin S., Myasoedov A., Poletaev N., Rodin S. // J. Cryst. Growth. 2017. V. 457. P. 202-206.

[7] Wang W., Wang H., Yang W., Zhu Y., Li G. // Sci. Rep. 2016. V. 6. P. 1-11.

[8] Huang C.C., Chang S.J., Kuo C.H., Wu C.H., Кo C.H., Wann Cl.H., Cheng Y.C., Lin W.J. // J. Electrochem. Soc. 2011. V. 158. P. H626-H629.

[9] Smirnov V.K., Kibalov D.S., Orlov O.M., Graboshnikov V.V. // Nanotechnology. 2003. V. 14. P. 709-715.

[10] Bessolov V., Zubkova A., Konenkova E., Konenkov S., Kukushkin S., Orlova T., Rodin S., Rubets V., Kibalov D., Smirnov V. // Phys. Status Solidi B. 2019. V. 256. P. 1800268.

[11] Аксянов И.Г., Компан М.Е., Кулькова И.В. // ФТТ. 2010. T. 52. B. 9. C. 1724-1728.

[12] Bessolov V., Kalmykov A., Konenkov S., Konenkova E., Kukushkin S., Myasoedov A., Osipov A., Panteleev V. // Microelectron. Eng. 2017. V. 178. P. 34-37.

[13] Freitas J.A., Culbertson J.C., Mastro M.A., Kumagai Y., Koukitu A. // J. Cryst. Growth. 2012. V. 350. P. 33-37. 